\title{
Research on the Cultivation Mode of College Students' Innovation Ability
}

\author{
Jinzuo Han, Ming Duan
}

Department of Electrical Engineering, North China Electric Power University, Baoding, China

Keywords: College student, Innovation ability, Cultivation model

\begin{abstract}
This paper applies literature method and survey method. Based on the investigation of the basic elements of the cultivation mode of college students' innovative ability, this paper explores the current situation of the main training models and analyzes the existing problems and causes of the cultivation mode of college students' innovative ability. From the aspects of curriculum system, teaching method, practice platform and security system, it is of great strategic significance to improve the cultivation mode of college students' innovation ability, which will promote the development of higher education.
\end{abstract}

\section{Introduction}

Background. Innovation means the courage to break the shackles of old ideas and concepts, the old model, is to solve the new problems and new achievements, open up a new situation of thought and spirit, in the complex and confused, hard case, breakthrough invention. Innovation capacity is the ability to introduce new things, specifically refers to the use of knowledge and theory, science, art, technology and various fields of practice continue to provide economic value, social value, ecological value of new ideas, new theories and new methods ability. As the main constructor of the future innovative country, the strength of independent innovation ability of university students is directly related to the success or failure of the construction of the innovation-oriented national strategy, which is related to the national rejuvenation and the rise and fall of the country. From the development trend and conditions of college students themselves, college students increasingly become the main force of China's independent innovation. The cultivation of university students' independent innovation ability is a complex and systematic project involving many factors. Cultivating the innovation ability of university students is one of the basic tasks of higher education. The Higher Education Law stipulates that "the task of higher education is to cultivate highly qualified specialists with innovative spirit and practical ability". The traditional mode of training in achieving superior results at the same time also highlights its drawbacks. In the face of the background of speeding up the updating of knowledge economy and the need of national competitiveness and talents development, it is necessary to pay more attention to the cultivation of college students' innovation ability and to optimize the cultivation mode of college students' innovation ability.

Previous Research. The authors found that the undergraduates' lack of innovation ability. And she analyzes the reason of the insufficiency of innovation ability and puts forward the establishment of comprehensive mechanism: establishing the idea of innovative education, establishing the scientific practice teaching mechanism, establishing the guiding mechanism of teachers, establishing the research-oriented teaching mechanism, establishing incentive mechanism for teachers and students [1]; Qiu Guangping constructs the trinity model of university students' innovation ability, which is based on the course construction, taking the competition as the traction and the laboratory opening as the platform. This mode has the characteristics of being operable and teaching students according to their aptitude [2]; Chen Zhiyong believes that the "rigid" academic year restraining and hindering the innovation education of college students, the application of "flexible" credit system instead of "rigid" academic year, taking into account the different personality characteristics of students in order to develop their personality [3]; Wang Shenghuai believes that we should make full use of scientific 
research to cultivate the comprehensive innovation ability of college students, so that production, learning and research emerge collaborative development [4]; Zhang Yunjun systematically considers the three factors, the time factor of cultivating university students' independent innovation ability, the basic starting point of university students' independent innovation ability, and the basic situation of their environment [5]; Zhang Haiwen found that college students' innovation consciousness is not strong, innovation thinking is lacking, and innovation practice participation is little [6]; Wang Pei summed up a variety of patterns, According to different teaching objects, the use of appropriate training mode [7]; Jiang Weiping believed that the science store not only creates a new mode of cultivating college students' innovative ability, but also its strict organizational operation makes the work smoothly [8]; Li Guofeng studied the correlation between disciplinary competitions and the cultivation of innovation ability [9];/v Xiang upholds the mode of cultivating undergraduates' tutor responsibility system and builds the "Three in One" [10]; Zhai Hao combines knowledge transfer, capacity building and innovation education to establish long-term mechanism to cultivate college students' innovation ability [11]; Su Yurong analyzed the elements and structure of the cultivation mode of college students' innovation ability. He summarized three main training modes and analyzed the problems of these models and explained them [12].

Research Question. According to the previous studies, it was found that the improvement of training mode is an important factor in cultivating college students' innovation ability. This paper is based on the current situation of the elements of innovation ability training mode, analyzes the main problems and reasons of the main training mode in colleges. Organic integration of the various elements of the training model, So that each element to form an effective operating mechanism, optimize the existing main training mode and improve the effectiveness of innovation and training. The research questions to be answered from this research are the following: (1)What is the current situation of the cultivation of innovative ability?(2)What are the problems and reasons of the existing training mode?(3)What are the ways to solve the problem of cultivation mode?

\section{Materials and Methods}

Design. In order to understand the current situation of the training mode, we should start with the existing state of the elements of the training mode. This paper involves the literature research method and the questionnaire survey method. The literature research method is based on the existing objective reality material and thought theory material, uses various logical and non-logical ways to process and organize, and reflects the objective laws of education in the form of theoretical thinking level knowledge. By collecting and collating the writings and literatures of a large number of relevant experts, we can understand the theories related to the cultivation mode of innovation ability of college students in the first section of the literature review, and provide a lot of valuable theoretical support for the research of this paper. The following will introduce the specific process of questionnaire survey.

Participants, Materials and Procedure. In order to understand and master the current situation of innovation ability of college students, taking the students and teachers of Yunnan University as an example, 500 students of different professions and different grades were investigated. From the perspectives of students to see the current situation of the cultivation of innovation ability.

Questionnaires were developed to establish a foundation for the research of the present situation. Mainly for students of innovative practice and foundation (curriculum system, teaching methods, practice platform three elements) to ask questions. Each investigator was asked the following questions: Whether the curriculum system, teaching method and practice platform of the school are conducive to cultivating students' innovation ability? 600 questionnaires were printed and distributed to the investigators, after which they were completed and collected. A total of 586 were recovered. 


\section{Results}

College students are the object of improving the innovation ability, respect the students 'subject status, and arouse the enthusiasm of the students, so as to continuously improve the students' innovation ability. The questionnaire mainly investigates the students' satisfaction with the curriculum system, teaching method, practice platform of the school and the problems in the training process.The results are shown in Table 1.

Table 1.Research results for students

\begin{tabular}{|c|c|c|c|}
\hline Question & Option & Number of samples & Percentage(\%) \\
\hline \multirow{4}{*}{$\begin{array}{l}\text { Whether the curriculum } \\
\text { system is conducive to } \\
\text { cultivating students' } \\
\text { innovative ability }\end{array}$} & very favorable & 18 & 3.5 \\
\hline & more favorable & 140 & 28.1 \\
\hline & no evaluation & 258 & 51.6 \\
\hline & unfavorable & 84 & 16.8 \\
\hline \multirow{4}{*}{$\begin{array}{l}\text { Whether the teaching method } \\
\text { is conducive to cultivate } \\
\text { students' innovation ability }\end{array}$} & very favorable & 15 & 2.9 \\
\hline & more favorable & 103 & 20.7 \\
\hline & no evaluation & 227 & 45.4 \\
\hline & unfavorable & 155 & 31 \\
\hline \multirow{4}{*}{$\begin{array}{l}\text { Whether the practice platform } \\
\text { is conducive to cultivate } \\
\text { students' innovation ability }\end{array}$} & very favorable & 22 & 4.3 \\
\hline & more favorable & 146 & 29.2 \\
\hline & no evaluation & 242 & 48.5 \\
\hline & unfavorable & 90 & 18 \\
\hline
\end{tabular}

The satisfaction of the factors in the training model of the school survey found that the overall situation of students more satisfied. Each factor in the evaluation of the largest proportion of no evaluation. In teaching methods, the proportion of unfavorable to cultivating students' innovative ability is higher than the other two factors. This shows that students' recognition of school training mode is not strong, especially for the teaching methods of the school.

\section{Discussion}

The Current Situation of the Cultivation of Innovative Ability. The first aim of this study was to investigate the current situation, In recent years, colleges to train innovative talents are very seriously, always attach importance to the cultivation of innovative ability. Compared with developed countries, China's institutions of higher learning have obvious shortcomings in the following aspects: the lack of high-level innovative talents, the limited role of Chinese universities in the national innovation system, and the lack of culture to encourage innovation in China's universities surroundings. The main existing training mode: Undergraduate Tutorial System and Production -Learning -Research Cooperation Mode.

The Problems and Reasons of the Existing Training Mode. There are many problems in the undergraduate tutorial system: there are many problems in the model of undergraduate tutor system: the dominant position of students' learning is neglected, and the dominant position of mentor teaching is highlighted. the limitations of personal knowledge are not conducive to the comprehensive development of students.

The efficiency of Production-Learning-Research Cooperation Mode is still low, it is difficult to form an effective force, the main reasons are the following aspects: Inconsistency of the main target to make the training effect can not form a concerted effort; The limitations of co-operation make the actual participation of students is not high; Teaching equipment behind the actual production, it is difficult to improve students practical ability.

The Ways to Solve the Problem of Cultivation Mode. Constructing the curriculum system to 
adapt to the cultivation of innovation ability. The following are some specific practices: Optimize the curriculum, construct the innovative curriculum system, enrich the elective courses, meet the needs of students' free study, develop interdisciplinary development, and cultivate the comprehensive ability of college students.

The use of innovative teaching methods, the use of innovative teaching methods. The following are some specific practices: the use of inquiry-based teaching methods, teaching and learning to use two-way interactive teaching methods, the use of modern educational technology teaching methods.

Constructing practice teaching, establishing practice platform and environment. The following are some specific practices: the construction of exploratory courses, the establishment of engineering workshop practice platform, the establishment of strategic alliance cooperation and practice platform.

Establish an efficient security system. Schools need to train high-quality teachers.. Teachers must master certain knowledge and methods of scientific research, have a certain scientific research ability and the ability to create new knowledge; Update and use of advanced teaching equipment, including sophisticated teaching and research equipment, electronic library equipment, campus Internet equipment; To create a good cultural and institutional environment. To build a free and open academic environment, so that colleges and universities have a comfortable running environment.

\section{Conclusions}

Our findings indicated that there are still many problems in the training mode. In the process of training should focus on the combination of awareness and practical activities, co-ordinate the training elements to achieve the training objectives. In the real construction of training mode, with the knowledge, ability and quality at the same time, create a good environment for the cultivation of innovative ability, which can protect the normal operation of innovation ability training model from external conditions, which is conducive to improving effectiveness of the innovation ability of college students.

\section{Acknowledgements}

This research is supported by the teaching reform project of North China Electric Power University.

\section{References}

[1] Shi Juhua, The Construction and Implementation of the Cultivation Mechanism of University Students' Innovation. Journal of Chongqing Institute of Technology, 2009. 23(5): p. 179-181.

[2] Qiu Guangping,Xia Xingyou, On the Cultivation Mode of College Students' Innovative Ability. Heilongjiang Researches on Higher Education, 2010. 3: p. 128-129.

[3] Chen Zhiyong, et al., Research on the Cultivation Mode of University Students' Innovative Ability from the Perspective of Credit System. Heilongjiang Researches on Higher Education, 2010. 8: p. 140-142.

[4] Wang Shenghuai, Cultivation Mode of University Students' Comprehensive Innovation Ability Based on Scientific Research Achievements. Experimental technology and management, 2015. 32(12): p. 9-12.

[5] Zhang Yunjun, Three dimensional model of College Students' independent innovation ability. Technology and innovation management, 2011. 32(6): p. 583-586.

[6] Zhang Wenhai, et al., The Double Helix Coupling Model of Cultivating College Students' Innovation. Higher Education in Architecture, 2015. 24(1): p. 151-154.

[7] Wang Pei, Research on the Cultivation Mode of College Students' Innovation Ability. Modern 
Education Science, 2003. 6: p. 99-101.

[8] Jiang Weiping, Science Store: A New Model of Cultivating College Students' Innovative Ability. Ideological and theoretical education, 2010. 23: p. 80-83.

[9] Li Guofeng,Zhang Shiying, et al., On the Cultivation Mode of College Students' Innovative Ability Based on Subject Competition. Experimental technology and management, 2013. 30(3): p. 24-26.

[10]Lv Xiang,Zhou Baotong, et al., Construction of "Three-in-one" Mode of Cultivating College Students' Innovative Ability. Journal of Science of Teachers' College and University, 2014. 34(3): p. 112-115.

[11]Zhai Hao, Research on the Cultivation Mode of Science and Technology Innovation Ability of College. Journal of Hefei University of Technology, 2011. 25(1): p. 9-12.

[12]Su Yurong, Research on the training mode of College Students' innovation ability. Wuhan University of Technology,2013. 